\title{
MITIGATION OF INJURY IN CANINE LUNG GRAFTS BY EXOGENOUS SURFACTANT THERAPY
}

Richard J. Novick, $\mathrm{MD}^{\mathrm{a}}$

Andrea A. Gilpin, MSc ${ }^{\mathrm{a}, \mathrm{b}}$

Kenneth E. Gehman, MD ${ }^{\mathrm{a}}$

Imtiaz S. Ali, $\mathrm{MD}^{\mathrm{a}}$

Ruud A. W. Veldhuizen, $\mathrm{PhD}^{\mathrm{c}}$

Jenifer Duplan, AHT ${ }^{\mathrm{a}}$

Lynn Denning, AHT ${ }^{a}$

Fred Possmayer, $\mathrm{PhD}^{\mathrm{d}}$

David Bjarneson, $\mathrm{PhD}^{\circ}$

James F. Lewis, $\mathrm{MD}^{\mathrm{c}}$
Background: Exogenous surfactant therapy of lung donors improves the preservation of normal canine grafts. The current study was designed to determine whether exogenous surfactant can mitigate the damage in lung grafts induced by mechanical ventilation before procurement. Methods and results: Five donor dogs were subjected to 8 hours of mechanical ventilation (tidal volume $45 \mathrm{ml} / \mathrm{kg}$ ). This produced a significant decrease in oxygen tension $(p=0.007)$ and significant increases in bronchoscopic lavage fluid neutrophil count $(p=0.05)$, protein concentration $(p=0.002)$, and the ratio of poorly functioning small surfactant aggregates to superiorly functioning large aggregates $(p=0.02)$. Five other animals given instilled bovine lipid extract surfactant and undergoing mechanical ventilation in the same manner demonstrated no significant change in oxygen tension values, lavage fluid protein concentration, or the ratio of small to large aggregates. All 10 lung grafts were then stored for 17 hours at $4^{\circ} \mathrm{C}$. Left lungs were transplanted and reperfused for 6 hours. After 6 hours of reperfusion the ratio of oxygen tension to inspired oxygen fraction was $307 \pm 63 \mathrm{~mm} \mathrm{Hg}$ in lung grafts administered surfactant versus $73 \pm 14 \mathrm{~mm}$ $\mathrm{Hg}$ in untreated grafts $(p=0.007)$. Furthermore, peak inspired pressure was significantly $(p<0.05)$ lower in treated animals from 90 to 360 minutes of reperfusion. Analysis of lavage fluid of transplanted grafts after reperfusion revealed small to large aggregate ratios of $0.17 \pm 0.04$ and $0.77 \pm$ 0.17 in treated versus untreated grafts, respectively $(p=0.009)$. Conclusions: Instillation of surfactant before mechanical ventilation reduced protein leak, maintained a low surfactant small to large aggregate ratio, and prevented a decrease of oxygen tension in donor animals. After transplantation, surfactant-treated grafts had superior oxygen tension values and a higher proportion of superiorly functioning surfactant aggregate forms in the air space than untreated grafts. Exogenous surfactant therapy can protect lung grafts from ventilation-induced injury and may offer a promising means to expand the donor pool. (J Thorac Cardiovasc Surg 1997;113:342-53)
From the Transplantation-Immunobiology Group, Robarts Research Institute and the Division of Cardiovascular-Thoracic Surgery, London Health Sciences Center ${ }^{\text {a }}$, the Department of Plant Sciences, University of Western Ontario ${ }^{\text {b; }}$ the Lawson Research Institute and Division of Respiratory Medicine, St. Joseph's Health Centerc; the Departments of Biochemistry and Obstetrics and Gynecology, MRC Group in Fetal and Neonatal Health and Development, University of Western Ontario ; and bLES Biochemicals Inc. ; London, Ontario, Canada.

Supported by the Heart and Stroke Foundation of Ontario, the Ontario Thoracic Society, and the MultiOrgan Transplant Service, London Health Sciences Center.
Read at the Seventy-sixth Annual Meeting of The American Association for Thoracic Surgery, San Diego, Calif., April 28-May 1, 1996.

Received for publication May 17, 1996; revisions requested July 22, 1996; revisions received Sept. 16, 1996; accepted for publication Sept. 18, 1996.

Address for reprints: Richard J. Novick, MD, Division of Cardiovascular-Thoracic Surgery, London Health Sciences Center, University Campus, P.O. Box 5339, London, Ontario, Canada N6A 5 A5.

Copyright (C) 1997 by Mosby-Year Book, Inc.

$0022-5223 / 97 \$ 5.00+0 \quad \mathbf{1 2} / \mathbf{6} / \mathbf{7 8 0 4 4}$ 
$T^{\mathrm{h}}$ he practice of lung transplantation remains constrained by a severe shortage of suitable donor organs. ${ }^{1}$ Although lung graft ischemic times of more than 6 hours are now commonplace clinically, recent registry reports have confirmed that the number of lung transplantation procedures done worldwide has reached a plateau since 1993 . $^{2}$ This may be, in part, due to the fact that more than $75 \%$ of multiorgan donors have lungs that are not suitable for transplantation because of edema, aspiration, infection, ventilator-induced lung injury, or pulmonary contusion. ${ }^{3,4}$ Although the successful outcome of lung transplantation is not compromised if donor lungs with mild hypoxemia, chronic tobacco exposure, or a minor contusion or infiltrate are used, ${ }^{5}$ use of these lungs has not yet had a significant impact on the donor organ shortage. New strategies to improve the preservation of lung grafts from a wider population of donors are required to expand the donor pool.

Recent laboratory work demonstrated that reperfusion of lungs after a prolonged interval of ischemia results in significant endothelial cell damage and dysfunction of the alveolar type II cells that produce pulmonary surfactant. ${ }^{1}$ Previous studies have documented that endogenous surfactant was altered after transplantation and that the changes in surfactant composition and function in the ischemia-reperfusion injury induced by lung transplantation in $\operatorname{dog}_{5}{ }^{6}$ and rats ${ }^{7}$ resembled those observed in patients with the acute respiratory distress syndrome. ${ }^{8}$ Furthermore, work in our laboratory showed improved pulmonary function after 36 hours of preservation of normal canine lung grafts with the use of bovine lipid extract surfactant (bLES) therapy, as long as the bLES was administered to lung donors before the ischemic interval. ${ }^{9}$

Previous studies have shown that mechanical ventilation can result in an acute lung injury that is characterized by neutrophil infiltration, increased pulmonary vascular permeability, and hyaline membrane formation. ${ }^{10}$ Studies in several animal species have demonstrated that ventilation with high tidal volumes can rapidly cause this ventilation-induced injury. ${ }^{11-14}$ Recent work also showed that ventilation of normal lungs with tidal volumes of 13 to $15 \mathrm{ml} / \mathrm{kg}$ resulted in alterations of the alveolar surfactant system; specifically, the ratio of poorly functioning small surfactant aggregate forms (SA) to the superiorly functioning large surfactant aggregate forms (LA) was increased. ${ }^{15}$ In the clinical setting, many potential lung donors receive mechanical ventilation for prolonged intervals before brain stem death is declared. This period of ventilation may contribute to significant pulmonary dysfunction and endogenous surfactant abnormalities in these patients. ${ }^{1} \mathrm{We}$ have used this model of lung injury for the current studies to investigate further the role of exogenous surfactant therapy in lung transplantation, particularly with respect to donor lung preservation.

The objective of this study, therefore, was to determine whether exogenous surfactant administration can mitigate the lung injury induced by mechanical ventilation in canine lung grafts before procurement. We hypothesized that early administration of exogenous bLES to lung donors would decrease the pulmonary damage associated with mechanical ventilation and would therefore enable these "injured" grafts to exhibit satisfactory function after a prolonged interval of hypothermic storage and transplantation.

\section{Material and methods}

Animal preparation. Left single-lung transplantation was done in 10 pairs of conditioned, 20 to $25 \mathrm{~kg}$ mongrel dogs, as previously described. ${ }^{6,9}$ Donor and recipient animals were premedicated with xylazine, $1 \mathrm{mg} / \mathrm{kg}$, and atropine, $0.4 \mathrm{mg} / \mathrm{kg}$, both administered intramuscularly. Anesthesia was induced with thiopental sodium, $12 \mathrm{mg} / \mathrm{kg}$ intravenously, and maintained with $1 \%$ halothane by inhalation. Animals were intubated with a cuffed endotracheal tube and volume-cycled mechanical ventilation was begun. Neuromuscular blockade was achieved with intravenous pancuronium, $0.1 \mathrm{mg} / \mathrm{kg}$, which was repeated at necessary intervals to eliminate spontaneous breathing. All animals received humane care in keeping with the "Principles of Laboratory Animal Care" (National Society for Medical Research), the "Guide for the Care and Use of Laboratory Animals" (National Institutes of Health Publication No. 86-23, revised 1985), and the Specifications of the Council on Animal Care of the University of Western Ontario.

Donor operation. Before the commencement of highvolume ventilation in donor lungs, an Olympus flexible fiberoptic bronchoscope was inserted through a side port of the endotracheal tube and was wedged into a segmental bronchus in the right lower lobe. Thirty milliliters of warmed $\left(37^{\circ} \mathrm{C}\right) 0.9 \% \mathrm{NaCl}$ was infused through the instrument channel of the bronchoscope and immediately aspirated with a syringe with the use of gentle suction. Approximately $4 \mathrm{ml}$ of lavage fluid was then added to a tube containing $0.05 \mathrm{ml}$ of $15 \%$ ethylenediaminetetraacetic acid and a cell count of the lavage fluid was done with a Coulter STKR hematologic analyzer (Coulter Inc., Hialeah, Fla.). Additional lavage specimens were submitted for the analysis of total protein and surfactant SA and LA forms, as described later in this section.

All donor animals then received mechanical ventilation for 8 hours with use of the following settings: fraction of inspired oxygen $\left(\mathrm{FiO}_{2}\right)$ 1.0, positive end-expiratory pressure $5 \mathrm{~cm} \mathrm{H} \mathrm{H}_{2} \mathrm{O}$, tidal volume $45 \mathrm{ml} / \mathrm{kg}$, and rate 16 
breaths $/ \mathrm{min}$. Although tidal volumes of $45 \mathrm{ml} / \mathrm{kg}$ are not used clinically, we chose this volume for our studies to produce an experimental lung injury during this period of ventilation. During high-volume ventilation, the values of peak inspired pressure were recorded every 30 minutes and arterial blood gas values were measured on a Ciba Corning 238 blood gas analyzer (Ciba Corning Diagnostic Limited, Richmond Hill, Ontario) at the same intervals. After 8 hours, the bronchoscope was reintroduced into a bronchopulmonary segment in the right lower lobe that was different from the segment subjected to lavage previously. The lavage procedure was repeated and samples of lavage effluent were analyzed for cell count, total protein, and surfactant SA and LA.

A median sternotomy and anterior pericardiectomy were then performed. The superior and inferior venae cavae, ascending aorta, pulmonary artery (PA), and trachea were mobilized. Heparin sodium, 300 units $/ \mathrm{kg}$, was administered, followed several minutes later by an injection of prostaglandin $E_{1}$ (Upjohn Company, Don Mills, Ontario), $250 \mu \mathrm{g}$, into the PA. The donor animals then underwent PA flushing with $60 \mathrm{ml} / \mathrm{kg}$ of $4^{\circ} \mathrm{C}$ modified Euro-Collins solution. The heart was excised, followed by the double-lung block. The double-lung block was manually inflated to total lung capacity with $100 \% \mathrm{O}_{2}$ and was stored for 16 to 17 hours immersed in a $4^{\circ} \mathrm{C}$ circulating saline solution bath.

Recipient operation. Sixteen hours after the donor operation, weight-matched recipient dogs underwent a left posterolateral thoracotomy through the fifth intercostal space. The right PA was encircled with a heavy silk tie for subsequent snaring to obtain blood gas measurements of the isolated left lung. ${ }^{6,9}$ In addition, ultrasonic flow probes (Transonic Inc., Ithaca, N.Y.) were placed around both the left and right PA so that individual PA blood flow rates could be continuously monitored throughout the operation. The chest was closed with towel clips, and a small opening was left through which the right PA snare could be manipulated. The animals were placed in a supine position and baseline arterial blood gas values were measured. Isolated left lung blood gas measurements were then obtained, the chest was reopened, and a left pneumonectomy was performed. The left atrial cuff, $\mathrm{PA}$, and bronchus of the donor left lung were then anastomosed to those of the recipient, as previously described. ${ }^{6,9}$ The left lung graft was fully reinflated and the left PA clamp was removed, initiating reperfusion. The chest was closed with towel clips, the animal was placed in the supine position, and baseline postreperfusion values of arterial blood gases, peak inspired pressure, and individual PA blood flow rates were recorded. Throughout reperfusion, all animals received mechanical ventilation with an $\mathrm{FiO}_{2}$ of 1.0 , positive end-expiratory pressure of $5 \mathrm{~cm} \mathrm{H}_{2} \mathrm{O}$, rate of 16 breaths/min, and a tidal volume of $20 \mathrm{ml} / \mathrm{kg}$. The ratio of oxygen tension $\left(\mathrm{PO}_{2}\right)$ to $\mathrm{FiO}_{2}$, the carbon dioxide tension $\left(\mathrm{PCO}_{2}\right)$, the peak inspired pressure, and the individual PA blood flow rates were recorded at 30-minute intervals during 6 hours of reperfusion. At the end of reperfusion, the right PA snare was applied for 10 minutes, enabling measurements of blood gas values to be obtained during isolated perfusion of the left lung graft. The animals were then killed with an overdose of sodium pentobarbital. The heart was vented by incising the left atrial appendage, descending aorta, and main PA and the trachea was clamped at end inspiration. The double-lung block was removed and individual whole lung lavage procedures were done as described later in this section.

Exogenous surfactant administration. The surfactant preparation used in these experiments was a lipid extract surfactant (bLES Biochemicals Inc., London, Ontario) supplied at a concentration of $25 \mathrm{mg}$ phospholipids per milliliter. This surfactant preparation has been used in multicenter clinical trials involving neonates with respiratory distress syndrome ${ }^{16}$ and has been investigated in transplantation $^{9}$ and nontransplantation ${ }^{17}$ lung injury models in animals.

Radiolabeled exogenous surfactant was prepared as follows. Initially, $0.2 \mathrm{ml}$ bLES was extracted into $\mathrm{CHCl}_{3}$ according to the method of Bligh and Dyer. ${ }^{18}$ The upper aqueous phase was discarded and to the lower chloroform phase was added $10 \mu \mathrm{Ci}$ 1,2-dipalmitoyl-L-3 phosphatidyl [N-methyl $\left.{ }^{3} \mathrm{H}\right]$ choline (40 to $85 \mathrm{mCi} / \mathrm{mmol}$, Amersham, Life Science, Oakville, Ontario). The mixture was then dried under a stream of nitrogen. Next, $0.5 \mathrm{ml} 0.9 \% \mathrm{NaCl}$ and a few glass beads were added to the dried material and the tube was capped and vortexed at maximum speed for 5 minutes. The resuspended surfactant was then removed and was added to a tube containing the bulk of the bLES. This tube was inverted several times to obtain uniform mixing of the radioactive material.

In donor animals that received instilled surfactant, ${ }^{3} \mathrm{Hj}$-labeled bLES, $100 \mathrm{mg} / \mathrm{kg}$, was administered via a No. 16 Foley catheter inserted through a side port of the endotracheal tube. Half the dose was given with the animal in the right recumbent and the other half in the left recumbent position. Each dose was followed by $20 \mathrm{ml}$ of room air; the Foley catheter was then removed and ventilation was resumed.

Experimental groups. Animals were randomly assigned to one of the following groups: (1) treatment of donor animals with instilled bLES immediately after the onset of high-volume ventilation (instilled bLES group), $n=5$, and (2) no treatment to donor lungs (control group), $n=$ 5 .

Surfactant aggregate isolation and total protein measurement. Bronchoscopic lavage fluid specimens from the donior lungs before and after high-volume ventilation, individual whole lung lavage fluid samples from the donor right lung after 17 hours of storage, and samples from the transplanted left lungs and native right lungs of recipient dogs after 6 hours of reperfusion were analyzed. The remaining tissue of the individual lobes of the donor, transplanted, and native lungs was excised after the lavage procedure and homogenized with $0.9 \% \mathrm{NaCl}$ in a Waring blender. The total volume of each lobar homogenate was recorded and aliquots were extracted in chloroform: methanol.

The bronchoscopic lavage fluid specimens and the whole lung lavage fluid specimens were centrifuged at $150 \mathrm{~g}$ for 10 minutes at $4^{\circ} \mathrm{C}$ to remove cellular debris. The $150 \mathrm{~g}$ supernatant was then centrifuged for 15 minutes at $40,000 \mathrm{~g}\left(4^{\circ} \mathrm{C}\right)$. The $40,000 \mathrm{~g}$ pellet was resuspended in $0.9 \% \mathrm{NaCl}$ containing calcium chloride, $1.5 \mathrm{mmol} / \mathrm{L}$, and 


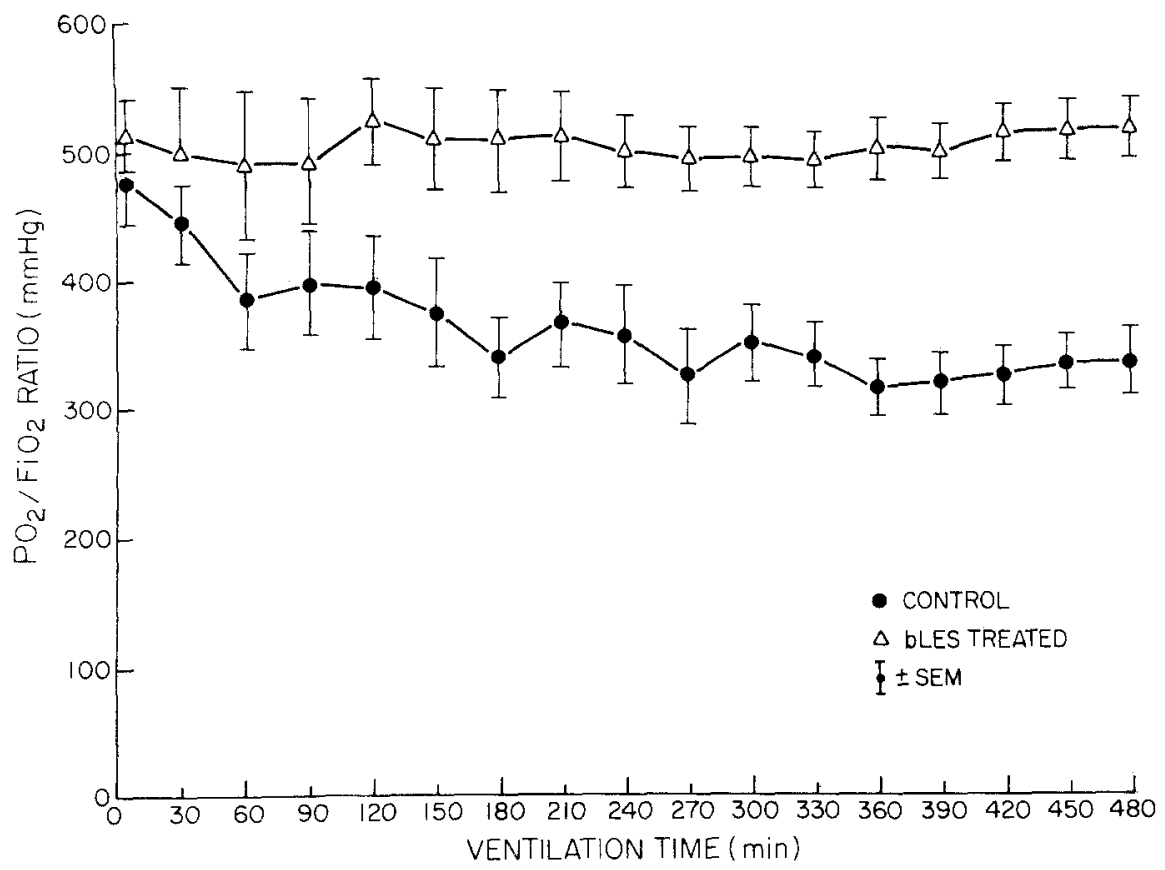

Fig. 1. $\mathrm{PO}_{2} / \mathrm{FiO}_{2}$ ratio (mean plus or minus standard error of the mean [SEM]) in the two experimental groups during 8 hours of high-volume ventilation in donor animals. Differences between groups, where significant, are stated in the text.

was designated as the LA fraction. ${ }^{11}$ The $40,000 \mathrm{~g}$ supernatant was designated as the SA fraction. ${ }^{9}$ Lipid extracts of aliquots of SA and LA were prepared by chloroform: methanol extraction according to the method of Bligh and Dyer. ${ }^{18}$ Total phospholipid content was determined by phosphorous analysis of aliquots of the lipid extracts by the method of Rouser, Fleischer, and Yamamoto. ${ }^{19}$ Total protein was quantified in the supernatant of the $40,000 \mathrm{~g}$ centrifugation by a modification of the method of Low1y and colleagues, ${ }^{20}$ with bovine serum albumin as a standard.

Exogenous surfactant recovery. Extracted aliquots of the lavage fluid specimens and lung homogenate samples of the instilled bLES group animals were dried under nitrogen and $\left[{ }^{3} \mathrm{H}\right]$ radioactivity was determined by liquid scintillation counting., ${ }^{9} 21$ Aliquots of the input radioactive surfactant used to treat these donor animals were extracted and counted by identical techniques. The total recovery of exogenous surfactant was calculated on the basis of the total radioactivity present in whole lung lavage fluid specimens and lung tissue analyzed after death divided by the total amount of radioactivity administered to the donor animals. In addition, the percent radioactivity of exogenous bLES in alveolar wash relative to lung tissue was calculated.

Statistical analysis. Results were expressed as means plus or minus the standard error of the mean. Statistical analysis included a repeated-measures analysis of variance assessment, with Dunnett's post hoc tests for sequential physiologic variables within each experimental group. In addition, unpaired, two-tailed $t$ tests were done on phys- iologic variables to compare results between experimental groups at each time interval. No adjustment was made for multiple testing over time. The changes in neutrophil count, protein concentrations, and SA/LA ratios in donor animal bronchoscopic lavage fluid samples were compared before and after 8 hours of high-volume ventilation by paired, two-tailed $t$ tests. Furthermore, the values of SA/LA ratios and total protein in bronchoscopic lavage fluid samples and whole lung lavage fluid samples were compared between groups by unpaired, two-tailed $t$ tests. The SAS statistical software program (Cary, N.C.) was used. A $p$ value less than 0.05 was considered significant.

\section{Results}

\section{Physiologic responses}

High-volume ventilation in donor animals. Before the institution of high-volume ventilation, all donor animals exhibited normal arterial blood gas values and peak inspired pressures (Figs. 1 and 2). The mean body weight of the donor dogs was $22.6 \pm 0.8$ $\mathrm{kg}$ in the control group and $21.4 \pm 1.2 \mathrm{~kg}$ in the instilled bLES group ( $p=0.44)$. The changes in $\mathrm{PO}_{2}$ during the 8 hours of high-volume ventilation are shown in Fig. 1. In the control group, the $\mathrm{Po}_{2}$ value significantly decreased over time $(p<0.001)$. Dunnett's procedure for comparing observations versus time 0 showed significant $(p<0.05)$ decreases in 

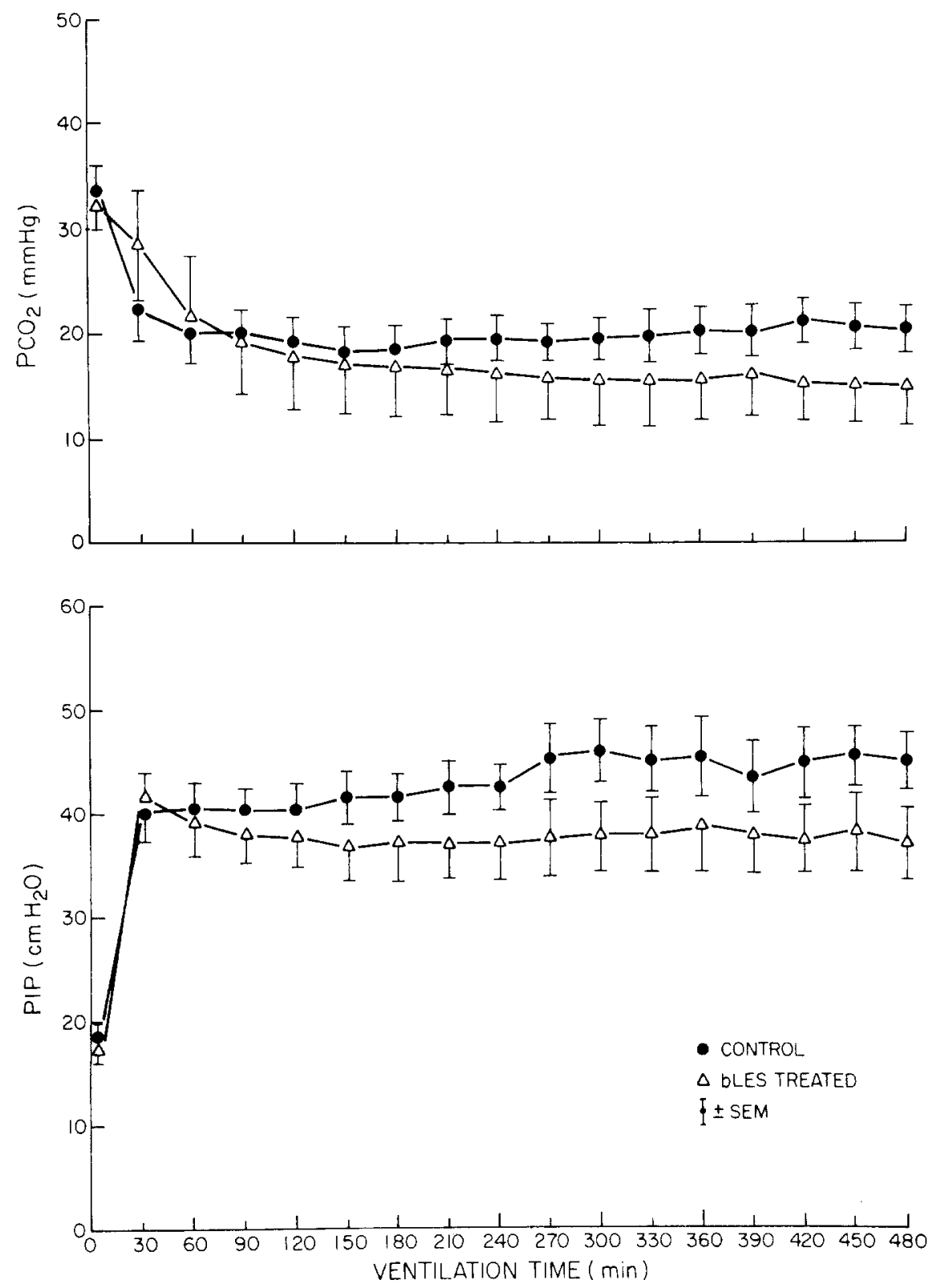

Fig. 2. Changes in values of $\mathrm{PCO}_{2}$ and peak inspired pressure (PIP) during 8 hours of high-volume ventilation in donor animals (mean plus or minus standard error of the mean [SEM]). There were no significant differences in $\mathrm{PCO}_{2}$ and PIP values between groups.

$\mathrm{PO}_{2}$ at 60 minutes and 150 to 480 minutes of donor ventilation. Animals in the instilled bLES group did not exhibit any significant change in $\mathrm{PO}_{2}$ values during the 8 hours of high-volume ventilation $(p=$ 0.99). The differences in $\mathrm{Po}_{2}$ values between groups became significant $(p<0.05)$ at 120 minutes of ventilation and remained significantly different during the next 6 hours of ventilation. Of note, the $\mathrm{PO}_{2}$ value at the end of 8 hours of high-volume ventila- tion in control animals $(337 \pm 27 \mathrm{~mm} \mathrm{Hg}$ ) still exceeded the threshold $\mathrm{PO}_{2} / \mathrm{FiO}_{2}$ value of $300 \mathrm{~mm}$ $\mathrm{Hg}$ that is regarded as acceptable by many clinical lung transplantation programs. As shown in Fig. 2, high-volume ventilation produced an immediate decrease in $\mathrm{PCO}_{2}$ values and an increase in peak inspired pressure values in both groups. From 30 to 480 minutes of ventilation, $\mathrm{PCO}_{2}$ values decreased significantly in control animals $(p=0.006)$ and in 


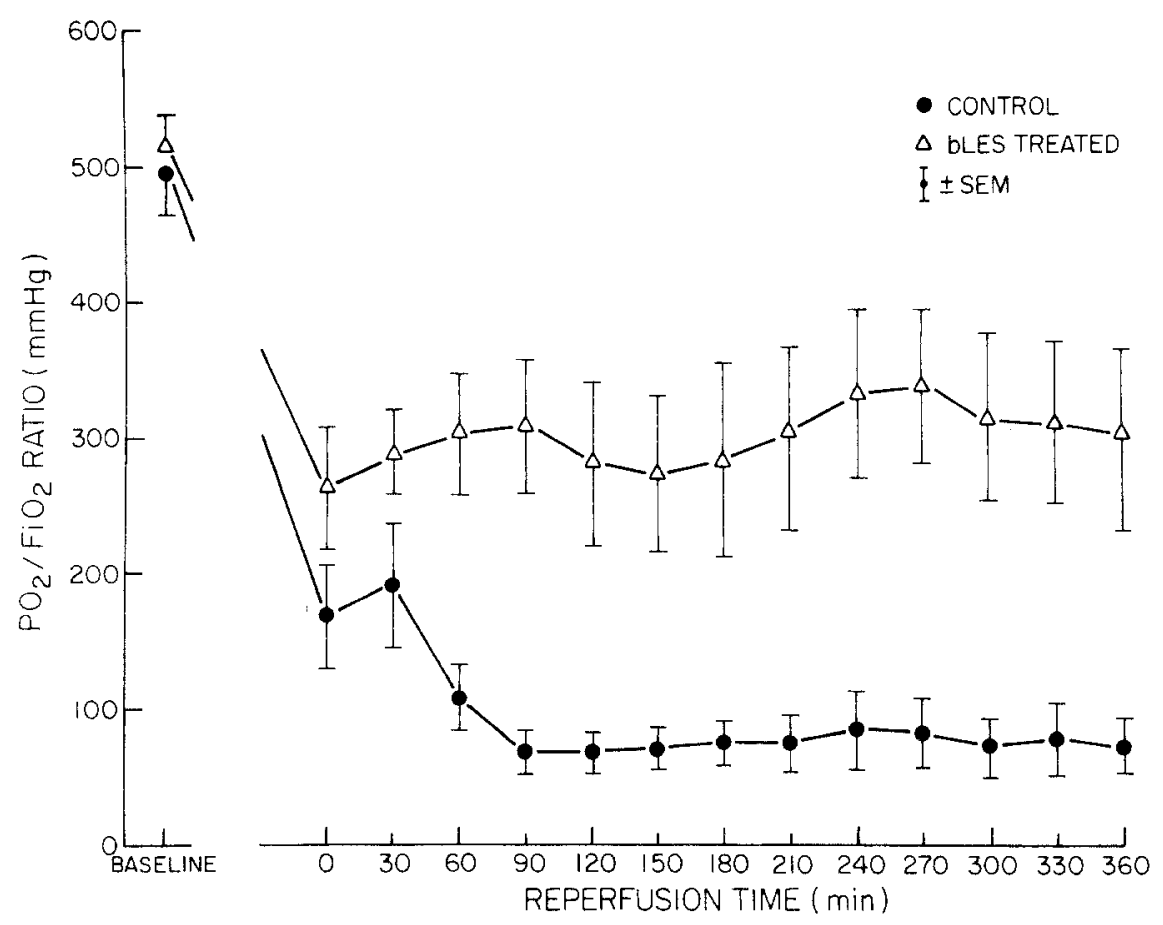

Fig. 3. $\mathrm{PO}_{2} / \mathrm{FiO}_{2}$ ratio (mean plus or minus standard error of the mean [SEM]) in the two experimental groups during reperfusion. Differences between groups, where significant, are stated in the text. Baseline, Pretransplantation $\mathrm{PO}_{2} / \mathrm{FiO}_{2}$ value.

instilled bLES animals $(p<0.001)$. Furthermore, peak inspired pressure values increased significantly from 30 to 480 minutes of ventilation in control dogs $(p<0.001)$, but did not significantly change in instilled bLES dogs $(p=0.065)$. Despite this withingroup difference in peak inspired pressure, there were no significant differences in values of $\mathrm{PCO}_{2}$ or peak inspired pressure between control and instilled bLES animals at any time during the 8 hours of high-volume ventilation.

Reperfusion in transplant recipients. The mean body weight of the recipient dogs was $24.6 \pm 0.5 \mathrm{~kg}$ in the control group and $26.1 \pm 1.6 \mathrm{~kg}$ in the instilled bLES group $(p=0.41)$. All lung transplant operations were performed by the same surgeon and the warm ischemic times were $50 \pm 2$ minutes and $49 \pm$ 3 minutes in control and instilled bLES animals, respectively $(p=0.84)$. The cold storage times were $16.7 \pm 0.3$ hours in the control and $16.5 \pm 0.1$ hours in the instilled bLES dogs $(p=0.54)$. The total ischemic times, therefore, were $17.5 \pm 0.2$ hours in the control group and $17.3 \pm 0.1$ hours in the instilled bLES group $(p=0.40)$. Before left pneumonectomy and left lung transplantation, the left PA blood flow rate was $412 \pm 67 \mathrm{ml} / \mathrm{min}$ in control dogs versus $388 \pm 25 \mathrm{ml} / \mathrm{min}$ in instilled bLES animals $(p=0.76)$. Immediately after transplantation, the left PA blood flow rate was $180 \pm 26$ $\mathrm{ml} / \mathrm{min}$ and $180 \pm 61 \mathrm{ml} / \mathrm{min}$ in control and instilled bLES dogs, respectively. There were no significant differences between groups in right or left PA blood flow rate at any time during reperfusion. At the end of reperfusion, the left PA blood flow rate was $372 \pm 83 \mathrm{ml} / \mathrm{min}$ in control dogs versus $364 \pm 52$ $\mathrm{ml} / \mathrm{min}$ in instilled bLES animals $(p=0.94)$.

Fig. 3 shows the mean $\mathrm{PO}_{2} / \mathrm{FiO}_{2}$ values for the two experimental groups during the 6-hour reperfusion period after transplantation. Baseline preoperative $\mathrm{PO}_{2} / \mathrm{FiO}_{2}$ values were similar in the two groups ( $p=$ 0.54 ). In the control group, the $\mathrm{Po}_{2} / \mathrm{FiO}_{2}$ value was significantly decreased at the onset of reperfusion as compared with the baseline preoperative value ( $p=$ 0.001 ) and the $\mathrm{PO}_{2} / \mathrm{FiO}_{2}$ value at the end of donor lung ventilation $(p=0.01)$. During reperfusion, there was a further significant decrease in $\mathrm{PO}_{2} / \mathrm{FiO}_{2}$ values in control animals compared with the initial posttransplant value (time 0) $(p=0.003)$. Dunnett's procedure for comparing observations versus time 0 showed significant $(p<0.05)$ decreases in $\mathrm{Po}_{2} / \mathrm{FiO}_{2}$ values at 90 to 210 minutes and at 300 and 360 


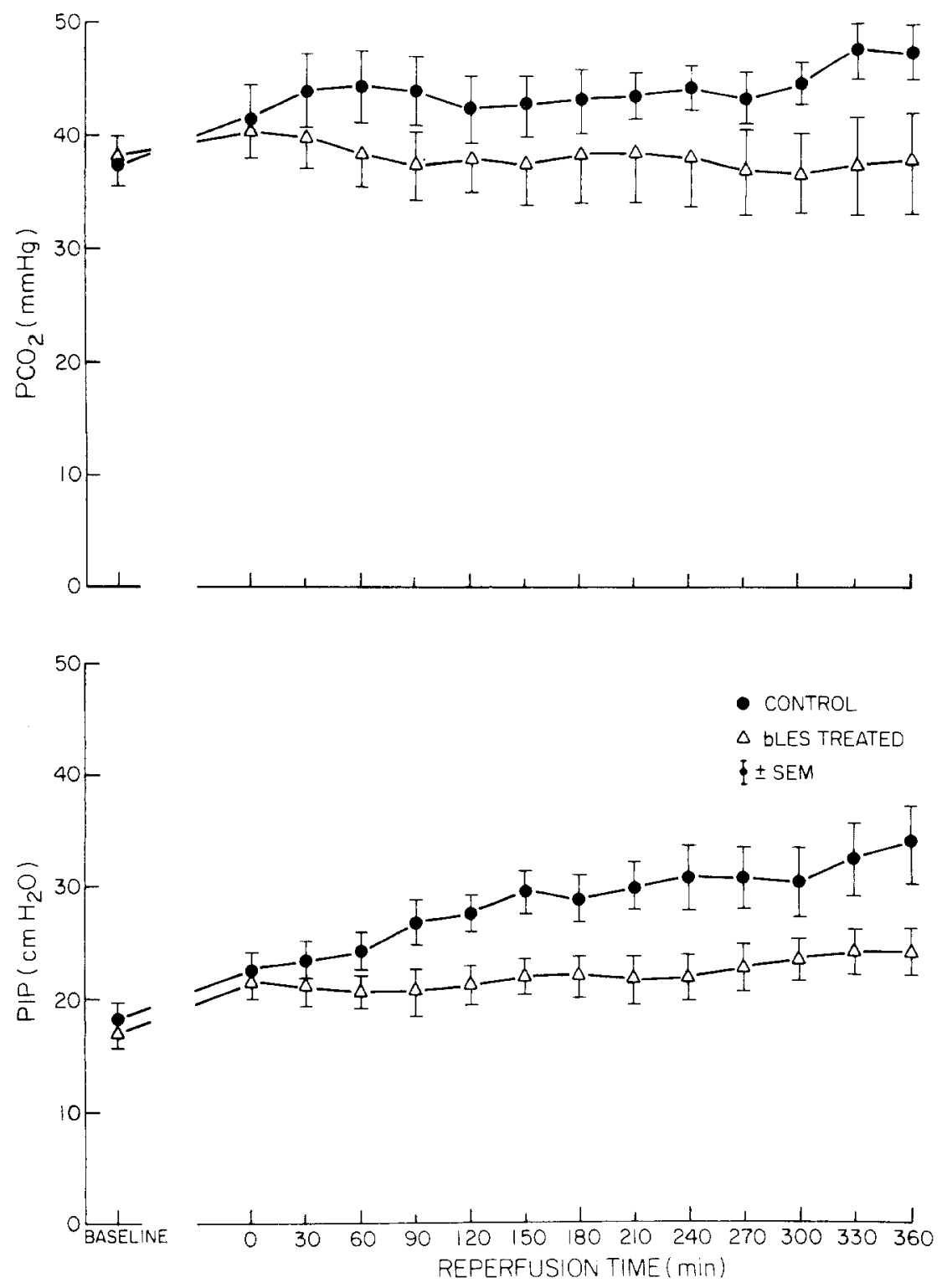

Fig. 4. Changes in values of $\mathrm{PCO}_{2}$ and peak inspired pressure (PIP) during reperfusion (mean plus or minus standard error of the mean [SEM]). Differences between groups, where significant, are stated in the text. Baseline, Pretransplantation $\mathrm{PCO}_{2}$ and peak inspired pressure values.

minutes of reperfusion in this group. In instilled bLES group animals, the $\mathrm{PO}_{2} / \mathrm{FiO}_{2}$ value immediately after transplantation was also significantly less than the baseline preoperative value $(p=0.004)$ and the $\mathrm{PO}_{2} / \mathrm{FiO}_{2}$ value at the end of donor lung ventilation $(p=0.004)$. However, there were no further significant changes in $\mathrm{PO}_{2} / \mathrm{FiO}_{2}$ values in the instilled bLES group dogs during the 6 hours of reperfusion $(p=0.91)$. Differences in $\mathrm{Po}_{2} / \mathrm{FiO}_{2}$ values between groups reached significance at 60 minutes $(p=$
$0.004)$ and remained significantly different for the remainder of the reperfusion interval $(p<0.01)$. A final assessment of oxygenation in the transplanted lung in each group was performed after 360 minutes of reperfusion by the right $\mathrm{PA}$ snaring technique. The isolated left lung $\mathrm{PO}_{2} / \mathrm{FiO}_{2}$ value was $54 \pm 26$ $\mathrm{mm} \mathrm{Hg}$ in control animals versus $225 \pm 49 \mathrm{~mm} \mathrm{Hg}$ in instilled bLES animals $(p=0.02)$.

The efficiency of ventilation during reperfusion, as assessed by mean $\mathrm{PCO}_{2}$ and peak inspired pres- 
sure values, is shown in Fig. 4. There were no significant changes in $\mathrm{PcO}_{2}$ values during reperfusion in either the control group $(p=0.09)$ or the instilled bLES group $(p=0.86)$ compared with the initial postreperfusion value (time 0 ). By $360 \mathrm{~min}-$ utes of reperfusion the $\mathrm{PCO}_{2}$ was $47.8 \pm 1.4 \mathrm{~mm} \mathrm{Hg}$ in control animals versus $38.2 \pm 4.1 \mathrm{~mm} \mathrm{Hg}$ in instilled bLES animals $(p=0.058)$. Peak inspired pressure values increased significantly in the control group during reperfusion $(p<0.001)$ as compared with the initial postreperfusion value. Dunnett's procedure for: comparing observations versus time 0 showed significant $(p<0.05)$ increases in peak inspired pressure values at 180 to 360 minutes of reperfusion in this group. In instilled bLES animals, peak inspired pressure values increased during reperfusion ( $p=0.01)$, but Dunnett's procedure showed significant $(p<0.05)$ increases in this variable only at 330 and 360 minutes compared with time 0 . Comparison of peak inspired pressure between groups showed significantly $(p<0.05)$ lower values in instilled bLES versus control animals from 90 to 360 minutes of reperfusion.

\section{Lung lavage fluid analyses}

Bronchoscopic lavage fluid analysis. Bronchoscopic lavage fluid neutrophil count, protein concentration, and SA/LA ratio before and after 8 hours of high-volume ventilation are shown in Table I. There were no significant differences in these variables between groups before the onset of high-volume ventilation (time 0 ). In the control group, 8 hours of high-volume ventilation produced significant increases in lavage fluid neutrophil count $(p=0.05)$, protein concentration $(p=0.002)$, and ratio of the poorly functioning SA to the superiorly functioning LA $(p=0.02)$ compared with the initial values. In the instilled bLES group, the lavage fluid neutrophil count was highly variable after 8 hours of highvolume ventilation and the increase in neutrophil count was not significant compared with the initial lavage fluid neutrophil concentration $(p=0.30)$. Furthermore, there were no significant increases in lavage fluid protein concentration $(p=0.11)$ after 8 hours of high-volume ventilation in the instilled bLES group. Comparison of bronchoscopic lavage fluid results between groups after high-volume ventilation revealed a trend toward lower protein values in the instilled bLES group versus those in the control group $(p=0.10)$. The surfactant SA/LA ratio was lower in the instilled bLES group, reflecting the fact that approximately $95 \%$ of the surfac-
Table I. Changes in bronchoscopic lavage fluid neutrophil count, protein concentration, and surfactant SA/LA ratios during high-volume ventilation

\begin{tabular}{lcccc}
\hline $\begin{array}{c}\text { Experimental } \\
\text { group }\end{array}$ & $\begin{array}{c}\text { Time } \\
(\mathrm{hr})\end{array}$ & $\begin{array}{c}\text { Neutrophil } \\
\text { count } \\
\left(\times 10^{6} / \mathrm{L}\right)\end{array}$ & $\begin{array}{c}\text { Protein } \\
(\mathrm{mg} / \mathrm{ml})\end{array}$ & $\begin{array}{c}\text { SA/LA } \\
\text { ratio }\end{array}$ \\
\hline Control & 0 & $43 \pm 39$ & $0.44 \pm 0.16$ & $0.86 \pm 0.15$ \\
& 8 & $1387 \pm 502$ & $2.42 \pm 0.26$ & $2.36 \pm 0.41$ \\
Instilled bLES & 0 & $11 \pm 6$ & $0.20 \pm 0.09$ & $0.66 \pm 0.36$ \\
& 8 & $665 \pm 554$ & $1.32 \pm 0.55$ & $0.91 \pm 0.22$ \\
\hline
\end{tabular}

See text for $p$ values.

tant lipid in bLES was in the surface-active LA form before instillation.

Whole lung lavage fluid analysis. The ratios of SA/LA in whole lung lavage fluid samples from (nonreperfused) donor right lungs, from native right lungs, and from transplanted left lung grafts of recipient animals after 6 hours of reperfusion are shown in Fig. 5. The SA/LA ratio in the donor right lungs of the instilled bLES group after 8 hours of high-volume ventilation and 17 hours of hypothermic storage was significantly lower than that in the control group $(p=0.003)$. After 6 hours of reperfusion, the SA/LA ratio in the native right lung of recipient animals was lower in instilled bLES animals than that in control animals $(p=0.05)$. The SA/LA ratio was also significantly lower in the instilled bLES group, as compared with that in the control group, in transplanted lungs that had undergone 6 hours of reperfusion $(p=0.009)$. There were no significant differences between the control and instilled bLES groups in total protein recovered from nonreperfused donor lungs $(p=0.22)$ and from the native right lungs $(p=0.44)$ and transplanted left lungs $(p=0.50$ ) of recipient animals (data not shown).

Recovery of exogenous surfactant. The total recovery of the instilled exogenous bLES, on the basis of the calculated $\left[{ }^{3} \mathrm{H}\right]$ label recovery in whole lung lavage fluid and tissue from donor, native, and transplanted lungs, was $64.3 \% \pm 1.5 \%(64.3 \mathrm{mg}$ phospholipid per kilogram body weight) in the instilled bLES group. Of the recovered exogenous surfactant, $47.1 \% \pm 2.1 \%$ was isolated from the nonreperfused donor right lung, $43.4 \% \pm 2.5 \%$ from the transplanted left lung, and $9.5 \% \pm 3.1 \%$ from the native right lung of the recipient animals. In the donor lungs, $60 \% \pm 10.8 \%$ of the total recovered bLES was obtained from the alveolar 


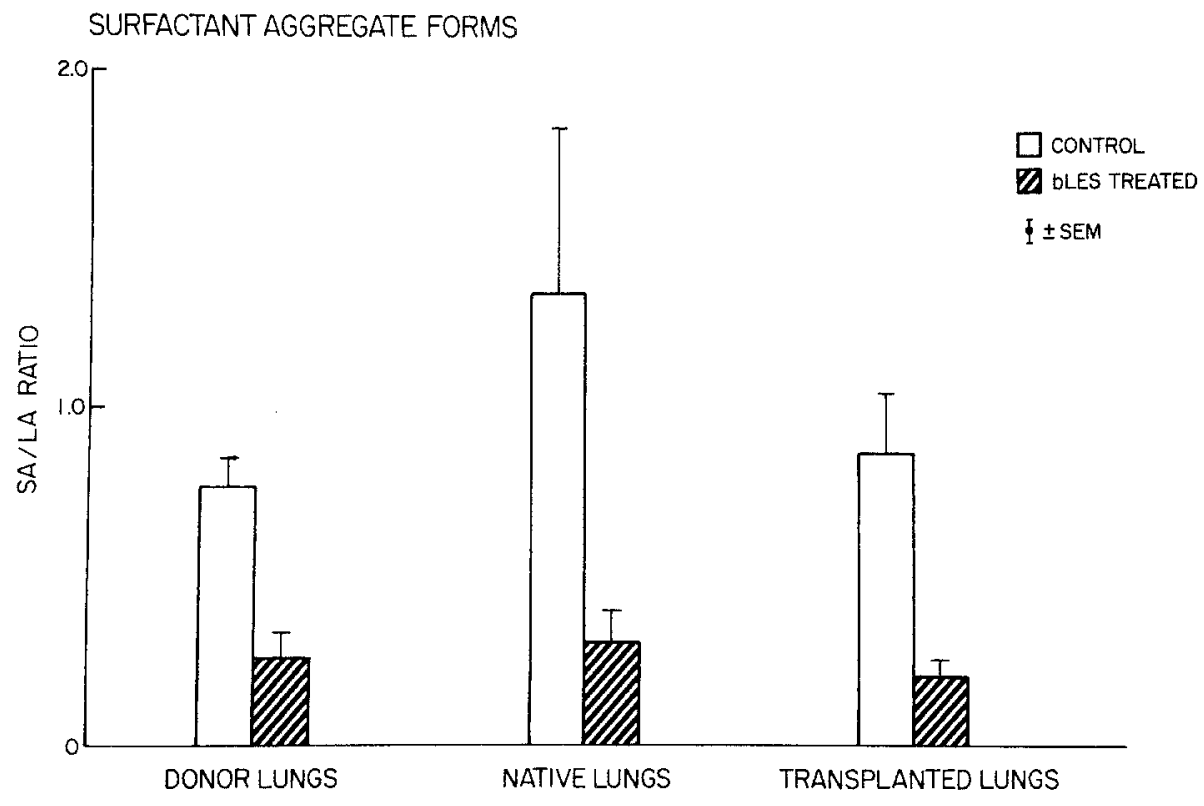

Fig. 5. The ratio of surfactant small aggregates to large aggregates in stored donor right lungs, in the native right lungs of recipient animals, and in transplanted left lung grafts after 6 hours of reperfusion. Differences between groups, where significant, are stated in the text. SEM, Standard error of the mean.

wash, relative to lung tissue. The percentage of radiolabeled bLES in the alveolar wash was $41.9 \%$ $\pm 5 \%$ in transplanted left lung grafts and $47.3 \% \pm$ $9.1 \%$ in the native right lungs of recipient animals. There were no significant differences in the percent recovery of radiolabeled bLES from the alveolar wash in donor, native, and transplanted lungs $(p=$ $0.36)$.

\section{Discussion}

During the past decade lung transplantation has evolved into a successful therapy for selected patients with end-stage respiratory and cardiorespiratory failure. Nonetheless, the shortage of suitable donor lungs remains a major limiting factor in pulmonary transplantation and accounts for the fact that since 1993 only approximately 1000 lung transplantations have been performed yearly by more than 110 clinical lung transplantation programs. $^{2}$ Laboratory studies have suggested that prevention of pulmonary endothelial cell damage and dysfunction of the alveolar type II cells that produce pulmonary surfactant is critical to the successful long-term preservation of lung grafts. ${ }^{1}$ Recent work in a rat lung transplant model showed that exogenous surfactant administered before reperfusion improved immediate posttransplantation lung function. ${ }^{22}$ In dogs, however, the improvement in oxy- genation during reperfusion by surfactant administration after 38 hours of ischemia was only modest, ${ }^{23}$ suggesting that earlier administration of exogenous surfactant may be superior. Indeed, subsequent experiments in our laboratory have demonstrated satisfactory 36 -hour preservation of normal canine lung grafts that received exogenous bLES before hypothermic storage of the graft. ${ }^{9}$ The results of these animal studies suggested that administration of exogenous surfactant to potential donors should be tested in clinical trials. In the clinical setting, however, most donor lungs are unsuitable for transplantation because of edema, aspiration, infection, ventilator-induced injury, or lung contusion. ${ }^{3,4}$ If the dysfunction of some of these grafts could be significantly reduced or even prevented by administration of exogenous surfactant to these lungs before procurement, a significant expansion of the pool of donor lungs would be possible.

A model of ventilation-induced lung injury was used in this study for several reasons. First, pilot studies in our laboratory demonstrated that mechanical ventilation of donor animal lungs for 8 hours with a tidal volume of $45 \mathrm{ml} / \mathrm{kg}$ predictably produced significant increases in bronchoscopic lavage fluid protein concentration and neutrophil counts, as well as moderate decreases in $\mathrm{PO}_{2} / \mathrm{FiO}_{2}$ values over this time. Despite this deterioration in 
lung function, these $\mathrm{PO}_{2} / \mathrm{FiO}_{2}$ values still exceeded the threshold value of $300 \mathrm{~mm} \mathrm{Hg}$ that is regarded as acceptable by many clinical lung transplantation programs. Second, transplantation of these grafts after 16 to 17 hours of hypothermic storage reproducibly resulted in poor gas exchange during reperfusion, thereby representing a suitable control group for these studies. Third, the model of ventilationinduced lung injury has been studied extensively, albeit in a nontransplantation setting, by numerous other investigators. ${ }^{11-14}$ Recent studies have also demonstrated that ventilation of rabbit lungs at a tidal volume of 13 to $15 \mathrm{ml} / \mathrm{kg}$, as compared with 8 to $10 \mathrm{ml} / \mathrm{kg}$, is associated with abnormal surfactant metabolism; specifically an increase in the conversion of the surface-active LA forms to the inactive SA forms in the air space. ${ }^{15}$ In the clinical setting, many lung donors with no evidence of aspiration, pulmonary edema, lung contusion, or infection have a markedly increased intrapulmonary shunt, ${ }^{1,24}$ possibly as a result of lung injury caused by mechanical ventilation. Moreover, a significant number of potential donor lungs that are suitable for procurement and subsequent transplantation are from a patient population that has received mechanical ventilation for prolonged periods. Our model of ventilation-induced lung injury is therefore clinically relevant to efforts to expand the pool of donor lungs and minimize posttransplantation pulmonary dysfunction.

In this study, the bronchoscopic lavage fluid neutrophil count increased markedly in the control group after 8 hours of mechanical ventilation, consistent with increased neutrophil infiltration of the lung grafts. The control and instilled bLES animals received ventilation in an identical manner and there were no significant differences between groups in $\mathrm{PCO}_{2}$ and peak inspired pressure values before lung procurement. Nevertheless, in control animals there were significant increases in lavage fluid protein concentration and the ratio of the poorly functioning SA to superiorly functioning LA after 8 hours of mechanical ventilation. Serum proteins have been shown to inhibit surfactant function both in vitro and in vivo. ${ }^{25,26}$ Moreover, previous studies have demonstrated that an increased concentration of surfactant SA relative to LA was associated with lung injury in transplantation ${ }^{6,9}$ and nontransplantation $^{8,27,28}$ animal models, as well as in patients with acute respiratory distress syndrome. ${ }^{29}$ Recent work has also revealed that exogenous surfactant is capable of mitigating the inflammatory response in vitro, ${ }^{30}$ although to our knowledge this has not yet been shown in vivo. In the current study, exogenous surfactant administration at the onset of ventilation decreased protein leak and resulted in more of the alveolar surfactant in the surface-active LA form. This in turn protected the lung from the adverse effects of positive pressure ventilation and prevented the deterioration of $\mathrm{PO}_{2}$ values in donor animals. The physiologic differences between the control and instilled bLES groups at the end of 8 hours of ventilation suggested that the latter group of lung grafts would be better able to tolerate a subsequent prolonged interval of hypothermic storage. Indeed, reperfusion of these lung grafts after transplantation resulted in superior $\mathrm{PO}_{2}$ values and improved ventilation efficiency in the instilled bLES group as compared with these values in animals given donor lungs that did not receive exogenous surfactant.

Interestingly, whole lung lavage fluid samples after 6 hours of reperfusion demonstrated that most of the exogenous surfactant remained in the surfaceactive LA form (Fig. 5), even though the treated grafts had received only a single dose of bLES 32 hours earlier. This may reflect the relatively large dose of instilled bLES that was administered to donor animals $(100 \mathrm{mg} / \mathrm{kg})$ and the fact that approximately $95 \%$ of the surfactant lipid in bLES was in the LA form before instillation. Alternatively, the LA forms in bLES may have been less susceptible to conversion to the inactive SA forms after transplantation. The surfactant recovery data demonstrated that $43.4 \% \pm 2.5 \%$ of the $\left[{ }^{3} \mathrm{H}\right]$-labeled bLES administered into the trachea of donor animals was present in transplanted left lung grafts during reperfusion, whereas only $9.5 \% \pm 3.1 \%$ had spilled over into the recipient's native right lung. Previous studies in lung transplantation models in rats $^{22}$ and $\operatorname{dogs}^{23}$ have shown that exogenous surfactant administered after prolonged graft storage can reduce lung injury during reperfusion, although earlier surfactant treatment of lung donors is more effective. ${ }^{9}$ The beneficial effects of bLES in the current study were thus not only a result of its ability to mitigate ventilation-induced injury in lung donors, but also of its ability to decrease lung injury during the critical early hours after transplantation.

Although the physiologic manifestations of lung injury caused by the combined effects of mechanical ventilation, lung graft storage, and transplantation were significantly reduced by donor bLES treatment, further studies need to be done to determine 
the extent to which exogenous bLES therapy can decrease histologic, morphometric, and ultrastructural pulmonary parenchymal damage in this model. In addition, other types of lung injury that are prevalent in multiorgan donors, such as edema, pulmonary infection, aspiration, and lung contusion, should be characterized in experimental lung transplantation models; the ability of exogenous surfactant therapy to salvage these lungs so that they may successfully be used for transplantation should be investigated. Because in the clinical setting most donor lungs exhibit significant dysfunction, a clinical trial to examine the safety and efficacy of exogenous surfactant therapy in potential donors should be undertaken. Moreover, innovative techniques to improve pulmonary endothelial cell function during donor lung injury, graft storage, and reperfusion must also be developed, since as a combination of treatment modalities will likely prove necessary to increase the number of lung grafts available for transplantation and to minimize posttransplant pulmonary dysfunction.

We acknowledge the assistance of Heather L. Motloch in manuscript preparation. Larry W. Stitt, MSc, provided expert advice in techniques of statistical analysis. The bLES was supplied by bLES Biochemicals Incorporated, London, Ontario, Canada.

\section{REFERENCES}

1. Novick RJ, Gehman KE, Ali IS, Lee J. Lung preservation: the importance of endothelial and alveolar type II cell integrity. Ann Thorac Surg 1996;62:302-14.

2. Hosenpud JD, Novick RJ, Breen TJ, Keck B, Daily P. The Registry of the International Society for Heart and Lung Transplantation: twelfth official report-1995. J Heart Lung Transplant 1995;14:805-15.

3. Sundaresan S, Trachiotis GD, Aoe M, Patterson GA, Cooper JD. Donor lung procurement: assessment and operative technique. Ann Thorac Surg 1993;56:1409-13.

4. Egan TM, Boychuck JE, Rosato K, Cooper JD. Whence the lungs: a study to assess suitability of donor lung for transplantation. Transplantation 1992;53:420-2.

5. Sundaresan $S$, Semenkovich J, Ochoa $L$, et al. The successful outcome of lung transplantation is not compromised by the use of marginal donor lungs. J Thorac Cardiovasc Surg 1995;109:1075-80.

6. Veldhuizen RAW, Lee J, Sandler D, et al. Alterations in pulmonary surfactant composition and activity after experimental lung transplantation. Am Rev Respir Dis 1993;148: 208-15.

7. Erasmus ME, Peterson AH, Oetomo SB, Prop J. The function of surfactant is impaired during the reimplantation response in rat lung transplants. J Heart Lung Transplant 1994;13:791-802.

8. Lewis JF, Jobe AH. Surfactant and the adult respiratory distress syndrome. Am Rev Respir Dis 1993;147:218-33.
9. Novick RJ, MacDonald J, Veldhuizen RAW, et al. Evaluation of surfactant treatment strategies after prolonged graft storage in lung transplantation. Am J Respir Crit Care Med 1996;154:98-104.

10. Hickling KG. Ventilatory management of ARDS: can it affect the outcome? Intensive Care Med 1990;16:219-26.

11. Dreyfuss D, Basset G, Soler P, Saumon G. Intermittent positive-pressure hyperventilation with high inflation pressures produces pulmonary microvascular injury in rats. Am Rev Respir Dis 1985;132:880-4.

12. Dreyfuss D, Soler P, Basset G, Saumon G. High inflation pressure pulmonary edema: respective effects of high airway pressure, high tidal volume, and positive end-respiratory pressure. Am Rev Respir Dis 1988;137:1159-64.

13. Fu Z, Costello ML, Tsukimoto $\mathrm{K}$, et al. High lung volume increases stress failure in pulmonary capillaries. J Appl Physiol 1992;73:123-33.

14. Parker JC, Townsley MI, Rippe B, Taylor AE, Thigpen J. Increased microvascular permeability in dog lungs due to high peak airway pressures. J Appl Physiol 1984;57:1809-16.

15. Veldhuizen RAW, Marcou J, Yao LJ, McCaig L, Lewis JF. Alveolar surfactant aggregate conversion in ventilated normal and injured rabbits. Am J Physiol 1996;270:L152-8.

16. Enhorning G, Shennan A, Possmayer F, Dunn M, Chen CP, Milligan J. Prevention of neonatal respiratory distress syndrome by tracheal instillation of surfactant: a randomized clinical trial. Pediatrics 1985;76:145-53.

17. Lewis JF, Goffin J, Yue P, McCaig LA, Bjarneson D, Veldhuizen RAW. Evaluation of two exogenous surfactant preparations and delivery methods in an adult model of acute lung injury. J Appl Physiol 1996;80:1156-64.

18. Bligh EG, Dyer WJ. A rapid method of total lipid extraction and purification. Can J Biochem Physiol 1959;37:911-7.

19. Rouser G, Fleischer S, Yamamoto A. Two dimensional thin layer chromatographic separation of polar lipids and determination of phospholipids by phosphorus analysis of spots. Lipids 1970;5:494-6.

20. Lowry OH, Rosenbrough NJ, Farr AL, Randall RJ. Protein measurement with the Folin reagent. J Biol Chem 1951;193: 265-75.

21. Lewis JF, McCaig LA. Aerosolized versus instilled exogenous surfactant in a nonuniform pattern of lung injury. Am Rev Respir Dis 1993;148:1187-93.

22. Erasmus ME, Petersen AH, Hofstede G, Haagsman HP, Oetomo SB, Prop J. Surfactant treatment before reperfusion improves the immediate function of lung transplants in rats. Am J Respir Crit Care Med 1996;153:665-70.

23. Novick RJ, Veldhuizen RAW, Possmayer F, Lee J, Sandler D, Lewis JF. Exogenous surfactant therapy in thirty-eight hour lung graft preservation for transplantation. J Thorac Cardiovasc Surg 1994;108:259-68.

24. Riou G, Guesde R, Jacquens Y, Duranteau R, Viars P. Fiberoptic bronchoscopy in brain-dead organ donors. Am J Respir Crit Care Med 1994;150:558-60.

25. Cockshurt AM, Weitz J, Possmayer F. Pulmonary surfactantassociated protein $A$ enhances the surface activity of lipid extract surfactant and reverses inhibition by blood proteins in vitro. Biochemistry 1990;29:8424-9.

26. Jobe AH. Protein leaks and surfactant dysfunction in the pathogenesis of respiratory distress syndrome. Eur Respir $\mathrm{J}$ 1989;2(suppl 3):27s-32s.

27. Lewis JF, Ikegami M, Jobe AH. Altered surfactant function 
and metabolism in rabbits with acute lung injury. $\mathbf{J}$ Appl Physiol 1990;69:2303-10.

28. Lewis JF, Veldhuizen R, Possmayer F, et al. Altered alveolar surfactant is an early marker of acute lung injury in septic adult sheep. Am J Respir Crit Care Med 1994;150:123-30.

29. Veldhuizen RAW, McCaig LA, Akino T, Lewis JF. Pulmonary surfactant subfractions in patients with the acute respiratory distress syndrome. Am J Respir Crit Care Med 1995;152:1867-71.

30. Roth MD, Pinto M, Golub SH, Shau H. Pulmonary surfactant inhibits interleukin-2-induced proliferation and the generation of lymphokine-activated killer cells. Am J Respir Cell Mol Biol 1993;9:652-8.

\section{Discussion}

Dr. Keith S. Naunheim (St. Louis, Mo.). I would like to know what percentage of the donor pool the authors think might be salvageable with this strategy. Certainly ventilator-induced injury is but one of a myriad of problems that can occur that will prevent harvesting of the lung. Do the authors think this is going to have a significant clinical impact?

Dr. Gehman. That is difficult to know. These studies are preliminary, but they do indicate that at least in this model of lung injury there is some potential to salvage some lost lung grafts.

Dr. Naunheim. One of the problems with surfactant therapy, especially in the adult, has to do with significant cost. Can the authors tell us what it might cost to salvage a lung harvest? I know that there are some pulmonologists who believe that surfactant therapy is prohibitive in terms of cost and certainly in the adult setting.

Dr. Gehman. That is true. The use of bLES in the neonatal population is costly, and there is no question that similar therapy in adult donors would also be costly, since it would require larger volumes of bLES to treat donors. There is no question, however, that the cost will decrease with time.

Dr. Thomas M. Egan (Chapel Hill, N.C.). How would the authors anticipate using this in a clinical setting to expand the donor pool and to differentiate those lungs that are dysfunctional because of some kind of acute respiratory distress syndrome from those that are dysfunctional because of the high incidence of aspiration and infection in brain-dead donors?

Dr. Gehman. At this time our work is centered on only one mechanism of lung injury. I would anticipate that if there was a patient who was receiving ventilator support for a prolonged period who had clear findings on the chest x-ray film, that would be the patient who would be considered for surfactant therapy.

Dr. Larry R. Kaiser (Philadelphia, Pa.). Am I correct in assuming that in this model the surfactant was given before the induction of the high tidal volume ventilation?

Dr. Gehman. We gave the surfactant simultaneously with the onset of high-volume ventilation. There is evidence in the literature that even ventilation at normal tidal volumes leads to significant alterations in the SA/LA ratio and impairments in the surfactant system. We have also conducted preliminary experiments that administered surfactant 3 hours after the institution of high-volume ventilation. After reperfusion in the recipient there was a return of oxygenation values to numbers similar to those seen in surfactant-treated donors who received surfactant at the onset of high-volume ventilation.

Dr. Kaiser. Therefore you have applied this treatment to an injury that has already begun and have been able to show some reversal. 